\title{
Response of Lettuce Germplasm to Salt Stress at Different Developmental Stages
}

\section{Pavli OI*, Kempapidis K, Maggioros L, Foti C, Panagiotaki E and Khah EM}

Department of Agriculture Crop Production and Rural Environment, School of Agricultural Sciences, University of Thessaly, Volos, Greece

*Corresponding author: Pavli OI, Department of Agriculture Crop Production and Rural Environment, University of Thessaly, Fytokoy Str., 38446, Volos, Greece

Received: June 12, 2021; Accepted: July 07, 2021;

Published: July 14, 2021

\begin{abstract}
Salinity is one of the most detrimental abiotic stresses leading to considerable yield and economic losses worldwide. Lettuce is a relatively salt sensitive species, thus placing the interest in the release of salt-tolerant cultivars to enhance production in saline soils. This study aimed at investigating the response of lettuce germplasm to salt stress at the germination and at the whole plant level and to examine possibilities of early selection for salt tolerant genotypes. Fifteen lettuce commercial varieties were initially screened for salt tolerance on the basis of seed germination and seedling growth potential under salt stress conditions $(0,50,100,150 \mathrm{mM} \mathrm{NaCl})$. The in vitro evaluation revealed the existence of considerable genetic variation related to salt tolerance at germination and allowed for the classification of genotypes into tolerant, moderately tolerant and sensitive to salt stress. Based on this classification, six cultivars were assessed at the whole plant level using plant height, chlorophyll content and fresh and dry biomass weight as evaluation criteria. Overall findings point to the existence of a satisfactory association of genotype performance between germination and later growth stages, thus suggesting the feasibility of screening for salt tolerance at early growth stages. This approach may considerably upgrade the efficiency of selecting suitable germplasm material for cultivation in saline soils or introgression into relevant breeding programs.
\end{abstract}

Keywords: Early selection; Genotype selection; Lettuce; Salt stress; Salt tolerance; Screening for tolerance

\section{Introduction}

As salty soils of arable land continue to increase globally, salinity becomes a major threat to modern agriculture due to its adverse effect on plant growth and productivity leading to limited potential of crop cultivation. Most plant species are sensitive to increased soil salinity at all stages of their lifecycle, including seed germination, seedling establishment, vegetative and reproductive growth $[1,2]$, while they do not survive when $\mathrm{NaCl}$ concentration exceeds 200mM [3-5]. Salinity impairs plant growth and development via water stress, ionic toxicity, oxidative stress and nutritional imbalance, with its effects reflecting the result of complex interactions at the physiological and biochemical level, negatively affecting metabolism, cell signaling and energy state [6-9]. More importantly, salinity effects are aggravated by a combination of different abiotic stresses present in the field, as salt stress is often interlinked with drought and extreme temperatures [10].

Although agronomic practices, such as proper water and soil management may enhance agricultural production under salinized soils, additional gains with these practices are not safeguarded. In this context, equipping crops with salinity tolerance is viewed as the most promising strategy to enable cultivation in affected soils and sustain crop productivity in the future. Adaptive strategies include regulation of photosynthesis, protein synthesis, ion homeostasis and osmolyte accumulation $[8,11,12]$, the latter being one of the most routinely employed tolerance approaches [13]. The success to developing saltresilient crops however, is largely dependent on understanding the salt stress responses and tolerance mechanisms. Despite progress so far achieved, breeding for salt tolerance is still subjected to challenges arising from the complex nature of tolerance traits, the magnitude of the $\mathrm{G} \times \mathrm{E}$ interaction components, the large number of genotypes that needs to be assessed under uniform field-selective environments as well as the limited availability of effective screening methods.

Lettuce (Lactuca sativa L.) is one of the most important leafy vegetables with its leaves providing a valuable source of antioxidant vitamins, carotenoids, caffeic acid and flavanols $[14,15]$. Lettuce is considered as a relatively salt sensitive species $[16,17]$, with salinity effects being phenotypically manifested in growth inhibition, peripheral burning and leaf discoloration. Stress-attributed symptoms further include inhibition of seed germination, reduced leaf water content, photosynthesis rate, chlorophyll content, root and shoot growth as well as fresh and dry biomass weight and increased $\mathrm{Na}^{+}$and $\mathrm{Cl}^{-}$ion concentration and lipid peroxidation [18-20]. Considering the detrimental effects of salinity, the development of salt-tolerant germplasm is of outmost importance in order to enhance lettuce production in saline soils. This study aimed at investigating the response of lettuce germplasm to salt stress at germination and at the whole plant level and to examine possibilities of early selection for salt tolerant genotypes.

\section{Materials and Methods}

\section{Plant material}

Lettuce germplasm was assessed in terms of salt stress tolerance at the stage of seed germination and early growth as well as at the whole plant level. At germination stage, a total of 15 cultivars belonging 
Table 1: Lettuce cultivars used for the evaluation of salt stress response at germination stage and at the whole plant level.

\begin{tabular}{|c|c|c|}
\hline \multicolumn{3}{|c|}{ Cultivars evaluated at germination stage } \\
\hline 'Lattuga Grandi Loghi-Brasiliana' (GLB) & 'Romana Paris Island' (RPI) & 'Lollo Bionda' (LB) \\
\hline 'Lattuga Lollo Rossa' (LR) & 'Santa Anna' (SA) & 'Geo Store Manchester' (GSM) \\
\hline 'Latugga Verde Degli Ortolani' (VDO) & 'Red Batavia' (RB) & 'Ortis Doris' (OD) \\
\hline 'Iceberg-Great Lakes 659’ (IGL) & ‘Green Batavia' (GB) & 'Romana Green Tower’ (RGT) \\
\hline 'Black Simson' (BS) & 'Romana Duna' (RD) & 'Romana Hot' (RH) \\
\hline \multicolumn{3}{|c|}{ Cultivars evaluated at the whole plant level } \\
\hline Tolerant & Moderately tolerant & Sensitive \\
\hline RGT & $\mathrm{RD}$ & GLB \\
\hline $\mathrm{RH}$ & GSM & RB \\
\hline
\end{tabular}

to the four main botanical groups, -romana, butterhead, crispheadiceberg and loose-leaf-, were evaluated in salt stress assays (Table 1). Based on the in vitro assays, genotypes were classified into three classes: tolerant, moderately tolerant and sensitive. At the whole plant level, 2 cultivars from each of these classes were selected and assessed for salt tolerance (Table 1).

\section{$\mathrm{NaCl}$ stress assays at germination phase}

Lettuce cultivars were initially assessed at the stage of seed germination and early seedling growth. Seeds were surface-sterilized for $5 \mathrm{~min}$ in $10 \%$ sodium hypochlorite (EMPLURA, Merck KGaA, Darmstadt, Germany) $/ \mathrm{H}_{2} \mathrm{O}$ solution, containing Tween-20, while gently mixing and washed $4 \mathrm{x}$ with excess of $\mathrm{dH}_{2} \mathrm{O}$. Sterilized seeds were sown on $1 / 2$ MS medium (Duchefa Biochemie) supplemented with different concentrations of $\mathrm{NaCl}(0,50,100$ and $150 \mathrm{mM} \mathrm{NaCl})$ (Merck KGaA). The plates were transferred to growth chamber and grown under controlled conditions $\left(25 / 18^{\circ} \mathrm{C}\right.$ day/night temperature and $16 \mathrm{~h} / 8 \mathrm{~h}$ light cycle).

The evaluation was based on germination percentage $\left(3^{\text {rd }}, 5^{\text {th }}, 7^{\text {th }}\right.$, $9^{\text {th }}, 12^{\text {th }}, 15^{\text {th }}$ and $18^{\text {th }}$ day $)$ and root and shoot length $(\mathrm{cm})\left(4^{\text {th }}, 10^{\text {th }}\right.$ and $15^{\text {th }}$ day). Seeds were considered germinated when the radicle had a length of at least $2 \mathrm{~mm}$. For each $\mathrm{NaCl}$ stress level-genotype combination, three biological replications (petri dish) of 15 seeds were used.

\section{$\mathrm{NaCl}$ stress assays at the whole plant level}

Based on the in vitro data, in total 6 cultivars were selected for evaluation of salt tolerance at the whole plant level. Sterilized seeds were sown in jiffy pots and, following transplantation to pots, healthy plants at the stage of 5-8 true leaves were irrigated with $\mathrm{NaCl}$ solutions $(0,50,100$ and $150 \mathrm{mM} \mathrm{NaCl})$, at 3-day intervals, over 6 weeks.

The response to salt stress was assessed on the basis of plant height ( $45^{\text {th }}$ day), total chlorophyll content, estimated from the average values of 2 fully expanded middle leaves at the 1/3 of the leaf apex using SPAD-502 Meter (Konica Minolta) ( $30^{\text {th }}$ and $45^{\text {th }}$ day), as well as fresh and dry biomass weight. To determine dry weight, samples were dried at $70^{\circ} \mathrm{C}$ for $24 \mathrm{~h}$. For each $\mathrm{NaCl}$ stress level-genotype combination, four biological replications (individual plants) were used. A total of 96 plants were evaluated.

\section{Statistical analysis}

The Variety X Stress level factorial experiments followed the completely random design layout and data were analyzed by ANOVA
( $p \leq 0.05$ ), according to the experimental design. The performance of genotypes was comparatively assessed within each stress level applied at the specified time intervals. Comparisons of stress level performance across genotypes and of genotype performance across stress, levels were also conducted. The significance of differences between pairs of means was assessed by the Student's LSD test ( $\mathrm{p}$ $\leq 0.05$ ). All statistical analyses were performed using JMP statistical software v. 8.

\section{Results}

\section{Response of lettuce cultivars under salt stress conditions at germination phase}

To determine the response of lettuce cultivars to salt stress at germination stage, seeds were germinated on medium containing different concentrations of $\mathrm{NaCl}(0,50,100$ and $150 \mathrm{mM})$. Overall data indicate that salt stress adversely affected seed germination and seedling growth, with the severity of effects being well correlated with the stress level. The analysis revealed the existence of considerable genetic variation related to the salt stress response.

Germination potential was affected by the $\mathrm{NaCl}$ stress level as well as by the genotype, as evidenced by the mean values of treatments across genotypes and the mean values of genotypes across treatments (Supplementary Table S1). In the absence of stress, germination of most cultivars commenced at the $3^{\text {rd }}$ day, yet significant differences were observed, with RPI, RGT, GLB and GSM showing the highest rates $(96.67-100 \%)$. An exception to such increased rates was noted in VDO, IGL and LB, whose germination was initiated later and remained at relatively low levels throughout the observation period (33.33 - 63.33\%) (Supplementary Table S1). Significant differences were also noted in germination rates under stress conditions. At the onset of germination ( $3^{\text {rd }}$ day), the rates of control and $50 \mathrm{mM}$ $\mathrm{NaCl}$-stressed plants differed significantly, while from the $5^{\text {th }}$ day onwards no differences were noted between the mean values of these treatments across genotypes (Supplementary Table S1). At 100 and $150 \mathrm{mM} \mathrm{NaCl}$ however, a significant decrease or total inhibition of germination was noted until the $9^{\text {th }}$ day, while extending the stress period revealed significant variance among genotypes. Although severely affected upon initial exposure at $150 \mathrm{mM} \mathrm{NaCl}$, RGT and $\mathrm{RH}$ appeared as the most tolerant cultivars (Table 2). Such superiority was also adequately reflected in their final mean response to all stress levels (94.18\%) (Supplementary Table S1). In contrast, GLB and RB presented satisfactory rates at $50 \mathrm{mM} \mathrm{NaCl}$, yet showed a significant decrease at 100 and $150 \mathrm{mM} \mathrm{NaCl}$ as compared to the controls (Table 
Table 2: Effect of $\mathrm{NaCl}$ stress on 15 lettuce genotypes at germination stage.

\begin{tabular}{|c|c|c|c|c|c|c|c|c|c|}
\hline \multirow{4}{*}{ Cultivar } & \multicolumn{9}{|c|}{ Decrease over control (\%) } \\
\hline & \multicolumn{3}{|c|}{ Final germination } & \multicolumn{3}{|c|}{ Final root length } & \multicolumn{3}{|c|}{ Final shoot length } \\
\hline & \multicolumn{9}{|c|}{$\mathrm{NaCl}$ concentration $(\mathrm{mM})$} \\
\hline & 50 & 100 & 150 & 50 & 100 & 150 & 50 & 100 & 150 \\
\hline GLB & 0 & 20 & 90 & 9.57 & 29.79 & 100 & 2.6 & 24.68 & 100 \\
\hline LR & 3.45 & 41.38 & 68.97 & 15.65 & 52.94 & 56.47 & 0 & 20.37 & 46.3 \\
\hline VDO* & 54.55 & 100 & 100 & - & - & - & - & - & - \\
\hline$I G L^{*}$ & 5.26 & 42.11 & 73.68 & - & - & - & - & - & - \\
\hline BS & 13.79 & 48.28 & 62.07 & 4.88 & 13.41 & 50 & -1.06 & 20.21 & 81.91 \\
\hline $\mathrm{RPI}^{*}$ & 10 & 90 & 100 & - & - & - & - & - & - \\
\hline SA & 4 & 12 & 4 & 5.97 & 41.34 & 68.66 & 1.52 & 40.91 & 68.18 \\
\hline GB & 10 & 10 & 40 & -1.16 & 20.93 & 45.58 & 37.66 & 37.66 & 76.62 \\
\hline $\mathrm{RD}$ & 0 & 3.33 & 73.33 & 3.49 & 18.6 & 60.47 & 4.49 & 21.35 & 78.65 \\
\hline $\mathrm{LB}^{*}$ & 10 & 50 & 80 & - & - & - & - & - & - \\
\hline GSM & 3.33 & 3.33 & 53.33 & -4.2 & 31.47 & 67.13 & 26.9 & 43.45 & 71.03 \\
\hline OD & 13.33 & 16.67 & 46.67 & 26.97 & 40.45 & 48.31 & 5.26 & 42.11 & 70.18 \\
\hline RGT & 0 & 3.33 & 20 & -3.28 & 14.75 & 31.15 & 9 & 23 & 62 \\
\hline $\mathrm{RH}$ & 0 & 3.33 & 20 & 5.97 & 17.91 & 74.63 & 3.94 & 18.74 & 69.29 \\
\hline
\end{tabular}

*Incapable of root and shoot formation throughout the period of observations.

2). At $150 \mathrm{mM} \mathrm{NaCl}, \mathrm{VDO}$-although of lower germinability to start with- along with RPI were incapable of germination during the entire stress period (Table 2, Supplementary Table S1).

In order to assess the post-germination growth potential, the root and shoot length was comparatively assessed within each stress level. The analysis revealed significant differences among genotypes and stress levels. In the absence of stress, root and shoot, length increased over time, yet cultivars differed considerably in relation to growth potential. LR, RB and GSM showed the highest values for root length, while the highest shoot length was noted in $\mathrm{BS}, \mathrm{RD}$, GLB and GB (data not shown). To the other end, VDO, IGL, RPI and LB proved incapable of root and shoot formation throughout the period of observations. In relation to root length, salt stress strongly affected all genotypes and the effects were analogous to its level. At the 4th day, most genotypes showed inability of root formation at both 100 and $150 \mathrm{mM} \mathrm{NaCl}$, while GSM was the only cultivar that developed roots at $150 \mathrm{mM} \mathrm{NaCl}$ (data not shown). At $15^{\text {th }}$ day, the root length of all cultivars drastically decreased at $150 \mathrm{mM} \mathrm{NaCl}$ while genotypic differences were maximized at $100 \mathrm{mM} \mathrm{NaCl}$. At this stress level, BS, RGT and RH showed the lowest decrease over controls, whereas RB and LR suffered the greatest losses (Table 2). In relation to shoot length, it was severely affected in all genotypes, showing a gradual decrease as $\mathrm{NaCl}$ concentration increased (Table 2). Salinity effects were obvious from the 4 th day, as evidenced by the inability of most genotypes to form shoots at 100 and $150 \mathrm{mM} \mathrm{NaCl}$, with the exception of GB, GSM, RGT and RH that formed shoots at $100 \mathrm{mM} \mathrm{NaCl}$ (data not shown). At $15^{\text {th }}$ day, the root length of all genotypes decreased drastically at $150 \mathrm{mM} \mathrm{NaCl}$ and was depleted in GLB and RB. At $100 \mathrm{mM} \mathrm{NaCl}, \mathrm{RH}$ and $\mathrm{RB}$ showed the lowest and highest decrease over controls respectively (Table 2).
Taking into account overall data from the in vitro evaluation, genotypes were classified into three phenotypic classes: tolerant, moderately tolerant and sensitive to salt stress. Based on this classification, 6 six-lettuce cultivars were selected and employed as germplasm for evaluation at the whole plant level: i) RGT and RH (tolerant), ii) GSM and RD (moderately tolerant) and iii) GLB and RB (sensitive). The germination rates and growth pattern of these cultivars at each stress level are comparatively depicted in Figure 1-3.

\section{Response of lettuce cultivars under salt stress conditions at the whole plant level}

For the evaluation at the whole plant level, the response of the selected 6 cultivars was assessed in plants irrigated with solutions differing in $\mathrm{NaCl}$ concentrations $(0,50,100$ and $150 \mathrm{mM})$ for a period of 6 weeks. Genotypic response was evaluated on the basis of plant height, chlorophyll content, fresh and dry biomass weight.

The analysis revealed that plant height was significantly affected by the stress level as well as by the genotype as evidenced by the mean values of treatments across genotypes and the mean values of genotypes across treatments (Table 3). The results point to a decreasing trend of plant height as $\mathrm{NaCl}$ concentration increased, leading to most drastic decrease at $150 \mathrm{mM} \mathrm{NaCl}$. RB and GSM were the best performing cultivars showing the lowest reduction compared with the controls at all stress levels applied. In contrast, RGT, which showed the highest height in controls, exhibited also the highest reduction upon stress (Table 4).

In relation to chlorophyll content, although the stress level performance across genotypes did not differ significantly, substantial differences were noted in the response of genotypes to salt stress (Table 3). The majority of genotypes showed an increase in chlorophyll content at all stress levels, with the exception of GSM 

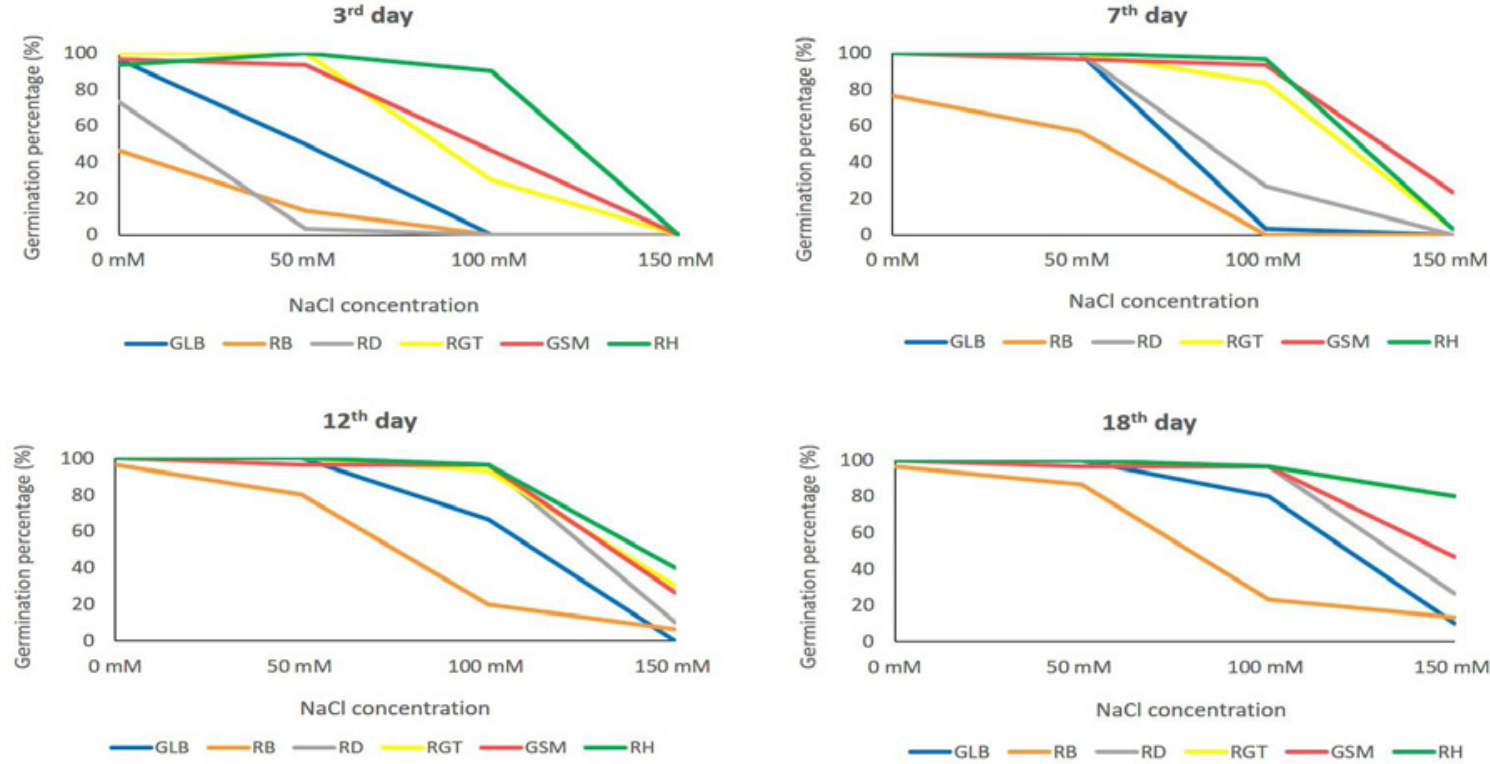

Figure 1: Germination rates of lettuce cultivars under normal and $\mathrm{NaCl}$ stress conditions ( $3^{\text {rd }}, 7^{\text {th }}, 12^{\text {th }}$ and $18^{\text {th }}$ day). The germination rates of $\mathrm{RGT}$, RH, GSM, RD, GLB and RB at each stress level $(0,50,100$ and $150 \mathrm{mM} \mathrm{NaCl})$ are comparatively depicted. Data are the means of three biological replications (petri dish) of 15 seeds.
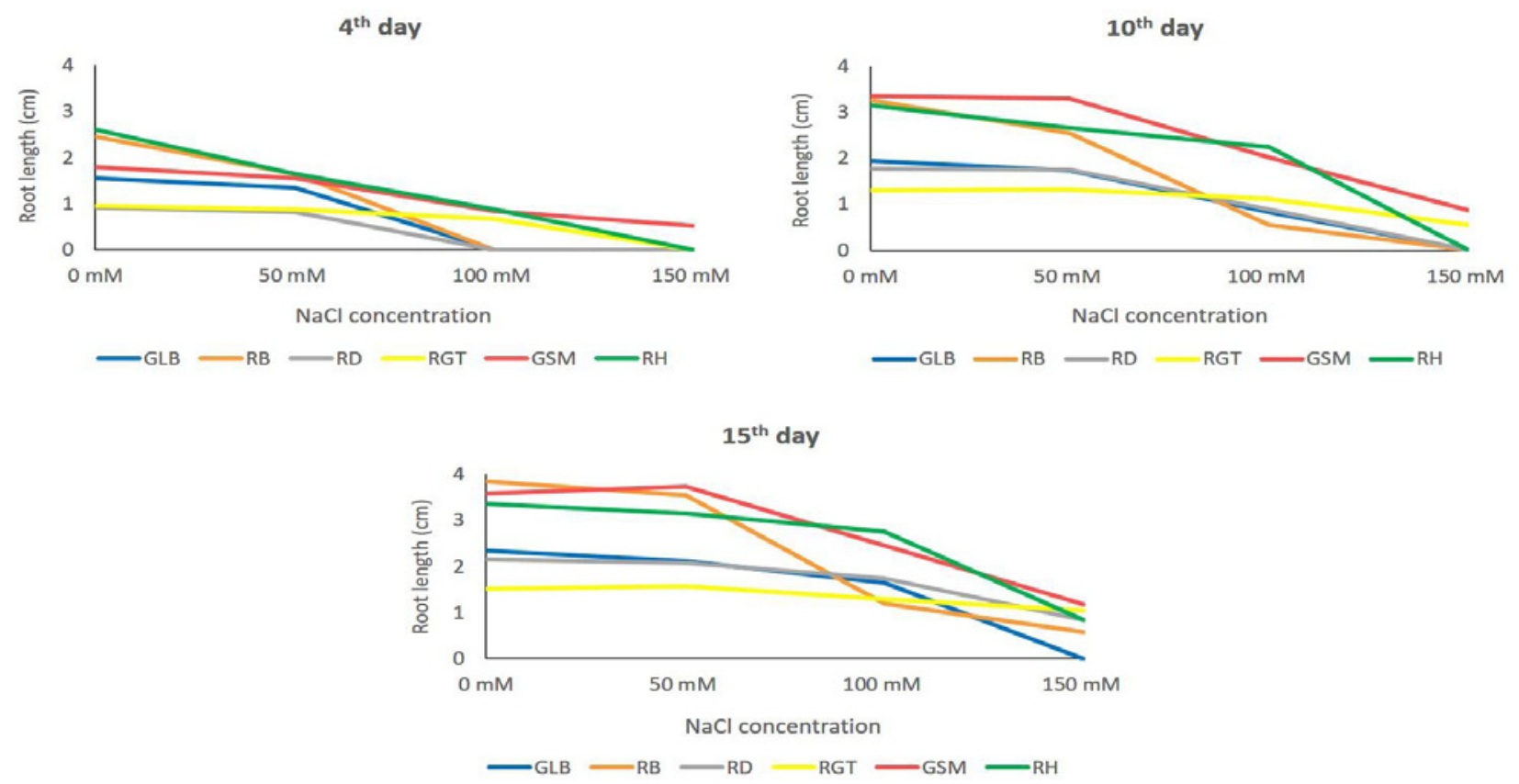

Figure 2: Root length $(\mathrm{cm})$ of lettuce cultivars under normal and $\mathrm{NaCl}$ stress conditions $\left(4^{\text {th }}, 10^{\text {th }}\right.$ and $15^{\text {th }}$ day). The root length of RGT, RH, GSM, RD, GLB and $\mathrm{RB}$ at each stress level $(0,50,100$ and $150 \mathrm{mM} \mathrm{NaCl})$ are comparatively depicted.

whose content was decreased (Table 4). In accordance with such observations, genotypes differed also at the phenotypic level. Most genotypes exhibited premature senescence of older leaves, chlorosis and necrosis, mostly confined in mature leaves, while GSM developed mild stress-attributed symptoms only at $150 \mathrm{mM} \mathrm{NaCl}$.

The fresh weight of lettuce plants was considerably affected both at the stress and at the genotype level (Table 3). In the absence of stress, RGT and RH showed the highest values whereas, RB presented the lowest values for fresh weight. Under stress conditions, a trend of decreasing weight was noted as $\mathrm{NaCl}$ increased, with the exception of RD and GSM whose fresh weight increased at $50 \mathrm{mM} \mathrm{NaCl}$ and decreased at 100 and $150 \mathrm{mM} \mathrm{NaCl}$. Among cultivars, GSM 

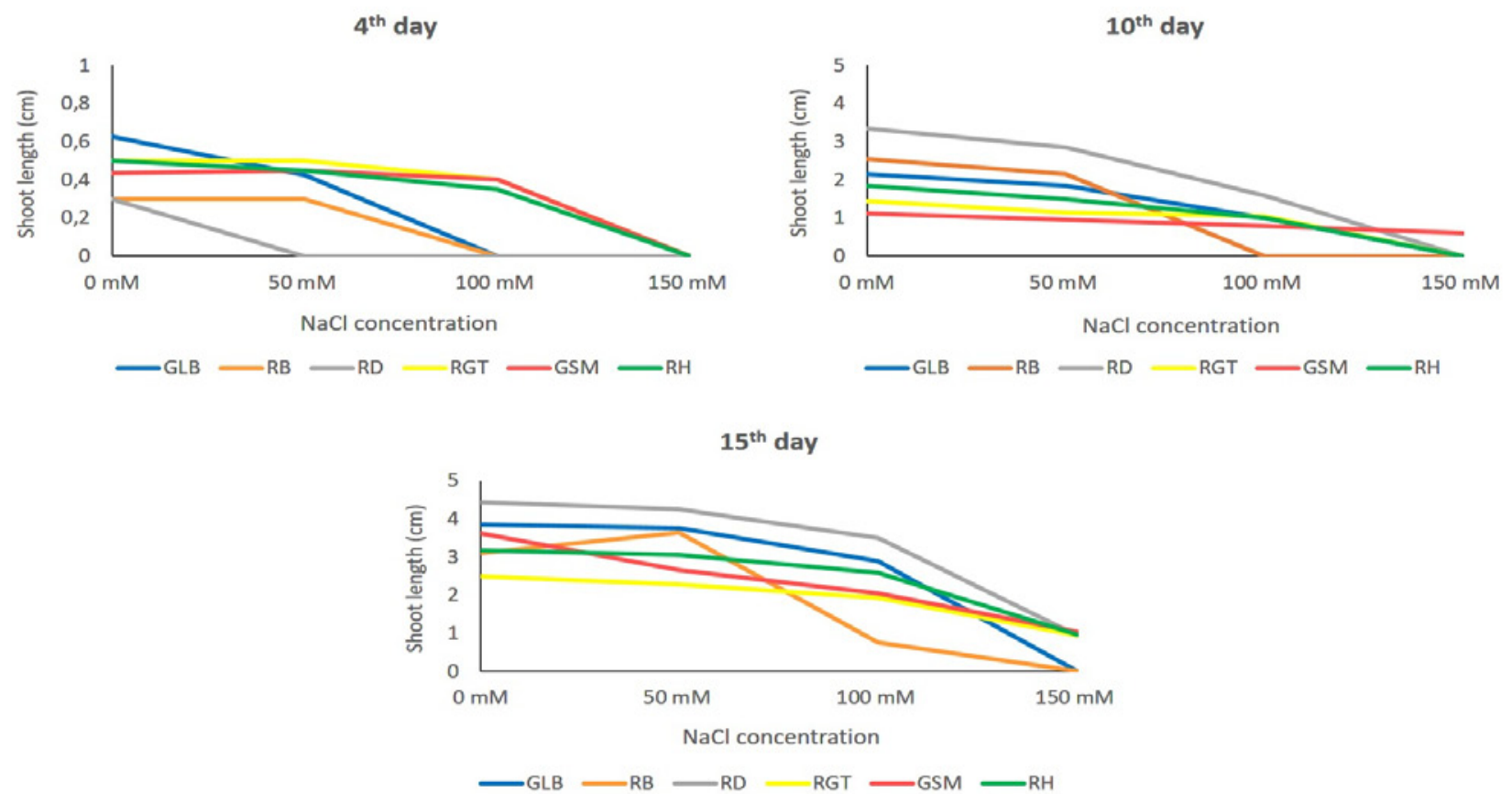

Figure 3: Shoot length $(\mathrm{cm})$ of lettuce cultivars under normal and $\mathrm{NaCl}$ stress conditions $\left(4^{\text {th }}, 10^{\text {th }}\right.$ and $15^{\text {th }}$ day). The shoot length of RGT, RH, GSM, RD, GLB and $\mathrm{RB}$ at each stress level $(0,50,100$ and $150 \mathrm{mM} \mathrm{NaCl})$ are comparatively depicted.

showed the lowest reduction, while GLB, RGT and RH, originally characterized of higher fresh weight, were most severely affected (Table 4). Dry weight was affected by salinity, yet stress effects were not in all cases associated with its level. Dry weight did not differ among controls and $50 \mathrm{mM} \mathrm{NaCl}$-stressed plants as well as among plants exposed to 100 and $150 \mathrm{mM} \mathrm{NaCl}$ (Table 3). Among cultivars, GLB and RB, although of lower dry weight to start with, showed the lowest decrease over controls (Table 4).

\section{Discussion}

As the salt-affected land is progressively increasing, mitigation of crop losses under saline conditions will inevitably rely on the release of salt tolerant cultivars. Although the effects of salts have been extensively studied in crop plants, the progress of relative breeding activities is still hampered by the complex nature of salt effects as well as the difficulties encountered in screening for salt tolerance. This study aimed at investigating the response of lettuce germplasm to salt stress both at germination and at the whole plant level and, further, to examine possibilities of selecting desirable genotypes at early growth stages. The evaluation of lettuce cultivars was performed on the basis of several physiological and growth parameters, including seed germination percentage, root and shoot length of seedlings, height of mature plants, total chlorophyll content as well as fresh and dry root weight and overall symptomatology.

The response of 15 commercial lettuce cultivars to salt stress was initially assessed at germination, which is viewed as a stage that is severely affected by salt stress, thus limiting the crop yield potential. Our findings revealed that both germination and seedling growth potential were adversely affected by salinity, with salt effects being well correlated to the stress level, yet considerable variation was noted among cultivars. Although GB initially showed a high germination ability at high stress levels, in the course of time RGT, RH and GSM proved as most tolerant based on their rates at all stress levels. To the other end, GLB and RB showed a drastically decreased germination at high stress levels, while in VDO and RPI germination was repressed at $150 \mathrm{mM} \mathrm{NaCl}$. The observed effects are in agreement with previous studies pointing to a reduced and delayed germination as $\mathrm{NaCl}$ concentration increases in lettuce $[18,21]$ as well as in other plant species [22-25]. The salinity effects were further depicted on root and shoot length, which showed a gradual decrease as $\mathrm{NaCl}$ concentration increased. Although all cultivars were drastically affected at high stress levels, significant differences were noted in their respective stress responses. In terms of growth potential, RGT proved as most tolerant cultivar, while GLB and RB ranked as most sensitive based on root and shoot length reduction at $150 \mathrm{mM} \mathrm{NaCl}$. Such findings are supportive of the previously reported salt effects on root and shoot growth in lettuce $[18,21,26]$, yet they are partly opposed to the suggestion that roots are more drastically affected than shoots in lettuce [27].

Overall data from the in vitro evaluation support the conclusion that seed germination and early growth potential under salt stress conditions may serve as reliable parameters for revealing the existing genetic variability as well as for classifying lettuce genotypes in terms of salt tolerance. As such, RGT, RH and SA proved relatively tolerant, GSM, RD, LR, BS, GB and OD were classified as moderately tolerant, whereas GLB and RB were ranked as most sensitive cultivars. VDO, IGL, RPI and LB were excluded from classification, as they proved incapable of root, shoot tissue formation in both control, and stressed plants. Based on such classification, 6 cultivars, namely RGT, RH, GSM, RD, GLB and RB, were assessed at the whole plant level using 
Table 3: Performance of 6 lettuce cultivars under normal and $\mathrm{NaCl}$ stress conditions.

\begin{tabular}{|c|c|c|c|c|c|c|}
\hline \multirow{2}{*}{ Day } & \multirow{2}{*}{ Genotype (G) } & \multicolumn{4}{|c|}{$\mathrm{NaCl}$ concentration $(\mathrm{mM})(\mathrm{C})$} & \\
\hline & & 0 & 50 & 100 & 150 & \\
\hline \multicolumn{7}{|c|}{ Plant height (cm) } \\
\hline \multirow[t]{8}{*}{$45^{\text {th }}$} & & & & & & Mean (C) \\
\hline & GLB & $23.03 c$ & $19.35 \mathrm{~cd}$ & $18.35 b$ & $17.15 \mathrm{bc}$ & $19.47 \mathrm{c}$ \\
\hline & $\mathrm{RB}$ & $25.20 b c$ & $25.70 a$ & $25.70 a$ & $21.45 a$ & $24.51 a$ \\
\hline & $\mathrm{RD}$ & $26.00 \mathrm{~b}$ & $23.00 \mathrm{~b}$ & $19.53 b$ & $18.75 b$ & $21.82 b$ \\
\hline & GSM & $16.45 \mathrm{e}$ & $15.08 \mathrm{e}$ & $14.13 d$ & $14.68 d$ & $15.08 d$ \\
\hline & RGT & $28.40 \mathrm{a}$ & $20.73 c$ & $19.23 b$ & $18.73 b$ & $21.77 b$ \\
\hline & $\mathrm{RH}$ & $20.35 d$ & $18.08 d$ & $16.40 c$ & $15.98 \mathrm{~cd}$ & $17.7 \mathrm{c}$ \\
\hline & Mean (G) & $23.24 a$ & $20.32 b$ & $18.89 c$ & $17.79 \mathrm{~d}$ & \\
\hline \multicolumn{7}{|c|}{ Chlorophyll content (SPAD values) } \\
\hline \multirow[t]{8}{*}{$30^{\text {th }}$} & & & & & & Mean (C) \\
\hline & GLB & $31.53 c$ & $33.10 a$ & $36.95 a$ & $37.10 a b$ & $34.67 b$ \\
\hline & $\mathrm{RB}$ & $36.93 a b$ & $36.23 a$ & $38.15 a$ & $40.35 a$ & $37.92 a$ \\
\hline & $\mathrm{RD}$ & $33.90 \mathrm{bc}$ & $33.08 a$ & $35.03 a$ & $32.55 \mathrm{ab}$ & $33.64 b$ \\
\hline & GSM & $39.35 a$ & $32.28 a$ & $33.60 a b$ & $31.08 \mathrm{c}$ & $34.07 b$ \\
\hline & RGT & $24.65 d$ & $30.15 a$ & $28.35 b c$ & $28.45 c$ & $27.9 \mathrm{c}$ \\
\hline & $\mathrm{RH}$ & $26.48 d$ & $28.20 a$ & $26.15 c$ & $28.78 \mathrm{c}$ & $27.4 \mathrm{c}$ \\
\hline & Mean (G) & $32.14 a$ & $32.17 a$ & $33.03 a$ & $33.05 a$ & \\
\hline \multirow[t]{8}{*}{$45^{\text {th }}$} & & & & & & Mean (C) \\
\hline & GLB & $32.93 a$ & $35.05 a$ & $40.65 a$ & $40.20 \mathrm{a}$ & $37.2 \mathrm{a}$ \\
\hline & $\mathrm{RB}$ & $35.70 a$ & $35.50 a$ & $37.65 a$ & $38.58 \mathrm{a}$ & $36.85 a$ \\
\hline & RD & $29.03 b$ & $35.15 a$ & $32.35 b$ & $32.28 b$ & $32.2 b$ \\
\hline & GSM & $35.45 a$ & $30.20 a b$ & $30.63 \mathrm{bc}$ & $27.48 \mathrm{c}$ & 30.94 \\
\hline & RGT & $23.40 c$ & $25.10 b$ & $27.85 c$ & $28.75 b c$ & $26.28 c$ \\
\hline & $\mathrm{RH}$ & $23.35 c$ & 29.98ab & $27.60 c$ & $27.33 c$ & $27.06 c$ \\
\hline & Mean (G) & $29.98 a$ & $31.83 a$ & $32.79 a$ & $32.44 a$ & \\
\hline \multicolumn{7}{|c|}{ Fresh weight (g) } \\
\hline \multirow[t]{8}{*}{$45^{\text {th }}$} & & & & & & Mean (C) \\
\hline & GLB & $83.27 a$ & $65.40 \mathrm{bc}$ & $61.45 b$ & $54.95 a$ & $66.27 a b$ \\
\hline & RB & $48.00 \mathrm{c}$ & $44.78 d$ & $38.43 d$ & $36.18 b$ & $41.84 d$ \\
\hline & $\mathrm{RD}$ & $67.48 b$ & 72.78ab & $55.43 c$ & $50.50 a$ & $61.54 \mathrm{bc}$ \\
\hline & GSM & $55.90 \mathrm{bc}$ & $59.88 c$ & $51.18 c$ & $50.00 a b$ & $54.24 c$ \\
\hline & RGT & $90.45 a$ & $77.03 a$ & $67.90 a$ & $55.68 a$ & $72.76 a$ \\
\hline & $\mathrm{RH}$ & $85.78 a$ & $66.60 \mathrm{bc}$ & 63.23ab & $60.05 a$ & 68.91ab \\
\hline & Mean (G) & $71.81 a$ & $64.41 b$ & $56.27 c$ & $51.23 d$ & \\
\hline \multicolumn{7}{|c|}{ Dry weight (g) } \\
\hline \multirow[t]{8}{*}{$45^{\text {th }}$} & & & & & & Mean $(\mathrm{C})$ \\
\hline & GLB & $7.47 b$ & $8.90 b c$ & $8.75 b$ & $7.90 a$ & $8.25 b$ \\
\hline & $\mathrm{RB}$ & $5.85 b$ & $6.45 c$ & $5.98 \mathrm{c}$ & $5.70 \mathrm{~b}$ & $5.99 c$ \\
\hline & $\mathrm{RD}$ & $11.10 a$ & $10.68 a$ & $8.85 b$ & $8.33 a$ & $9.74 a$ \\
\hline & GSM & $11.30 \mathrm{a}$ & $11.48 a$ & $9.88 a$ & $8.88 a$ & $10.38 a$ \\
\hline & RGT & $11.23 a$ & 10.28ab & $9.98 a$ & $9.13 a$ & $10.15 a$ \\
\hline & $\mathrm{RH}$ & $9.68 a$ & $8.40 c$ & $8.13 b$ & $8.48 a$ & $8.67 b$ \\
\hline & Mean (G) & $9.44 a$ & $9.36 a$ & $8.59 \mathrm{~b}$ & $8.07 \mathrm{~b}$ & \\
\hline
\end{tabular}

"Values followed by the same letter, within each factor, are not significantly different according to LSD ( $p \leq 0.05)$. plant height, chlorophyll content and fresh and dry biomass weight as evaluation criteria.

Plant height was considerably affected by salt stress, with most cultivars showing large relative reductions under salinity. The observed reductions were in general well correlated with the stress level but cultivars differed significantly in their response to the increasing stress intensity. Although most cultivars showed a gradual decrease in plant height, RB was only affected at $150 \mathrm{mM} \mathrm{NaCl}$ and GSM showed the lowest decrease over controls even at this stress level. Such results are consistent with previous studies highlighting the adverse effects of salinity on plant height [28]. Our findings further support previous suggestions that genotypes with high growth potential per se, as is the case of $\mathrm{RD}$ and $\mathrm{RGT}$, are more prone to growth reduction, whereas the ones of lower growth potential, such as GSM, suffer less relative losses [17]. Interestingly, the stress response of most genotypes involved an increase in chlorophyll content per leaf area, as evidenced by the increased SPAD values. The only exception to such increasing trend was noted in GSM, whose chlorophyll content decreased at all stress levels. Despite the general decreasing chlorophyll content as salt concentration increases [29], the opposite trend has been reported in various types of lettuce germplasm [17,30]. Such cumulative pattern, which is only characteristic of cultivated lettuce as wild $L$. serriola accessions show decreased chlorophyll index [31], has been associated with an increased accumulation of $\mathrm{NaCl}$ in the chloroplast [32] or an increased number of chloroplasts in stressed leaves [33]. In agreement with abovementioned observations, the phenotypic expression of salt stress was evident in the majority of cultivars, with the exception of GSM, which showed milder symptomatology.

Salinity effects were further depicted on the fresh and dry biomass weight of plants, which were in general decreased proportionally to the stress level. These findings are consistent with the previously reported decrease in fresh and dry weight of lettuce as salt concentration increased $[17,21,26,29]$. In our study, GSM showed the lowest reduction in fresh weight at all stress levels, while GLB and RB suffered the lowest losses in dry weight. Nonetheless, such performance is not considered as indicative of an enhanced tolerance but instead is related to their lower dry weight per se, as evidenced by the respective values in the controls.

Overall findings support the conclusion that the in vitro evaluation of lettuce genotypes at germination may be employed for revealing genetic variability related to salt tolerance. Addressing the classification of genotypes at germination phase, our data point to the existence of a satisfactory association of genotype performance between germination and later growth stages. Such association was evidenced by the relative superiority of RH and GSM at both evaluation stages and at all stress levels as well as by the sensitivity of GLB, which was expressed in the majority of traits. Our findings are further supportive of the previously stated hypothesis that the genotypic high growth potential is associated with salt sensitivity and vice versa [17]. In this context, relevant is the performance of RGT and RD, which, although exhibited an enhanced tolerance at germination stage, suffered significant losses at the whole plant level. An exception to the good association of genotype performance between stages applies for RB, which, although initially classified as sensitive, showed a good performance at later stages. The performance of this red variety may 
Table 4: Effect of $\mathrm{NaCl}$ stress on 6 lettuce cultivars at the whole plant level.

\begin{tabular}{|c|c|c|c|c|c|c|c|c|c|c|c|c|}
\hline \multirow{4}{*}{ Cultivar } & \multicolumn{12}{|c|}{ Decrease over control (\%) } \\
\hline & \multicolumn{3}{|c|}{ Plant height } & \multicolumn{3}{|c|}{ Chlorophyll content } & \multicolumn{3}{|c|}{ Fresh weight } & \multicolumn{3}{|c|}{ Dry weight } \\
\hline & \multicolumn{12}{|c|}{$\mathrm{NaCl}$ concentration $(\mathrm{mM})$} \\
\hline & 50 & 100 & 150 & 50 & 100 & 150 & 50 & 100 & 150 & 50 & 100 & 150 \\
\hline GLB & 15.9 & 20.32 & 25.53 & -6.44 & -23.44 & -22.08 & 21.46 & 26.2 & 34.01 & -19.14 & -17.14 & -5.76 \\
\hline RB & -1.98 & -1.98 & 14.88 & 0.56 & -5.46 & -8.07 & 6.71 & 19.94 & 24.63 & -10.26 & -2.22 & 2.56 \\
\hline $\mathrm{RD}$ & 11.54 & 24.88 & 27.88 & -21.08 & -11.44 & -11.2 & -7.85 & 17.86 & 25.16 & 3.78 & 20.27 & 24.95 \\
\hline GSM & 8.33 & 14.1 & 10.76 & 14.81 & 13.6 & 22.48 & -7.12 & 8.44 & 10.55 & -1.59 & 12.57 & 21.42 \\
\hline RGT & 27.01 & 32.29 & 34.05 & -7.26 & -19.02 & -22.86 & 14.84 & 24.93 & 38.44 & 8.46 & 11.13 & 18.7 \\
\hline $\mathrm{RH}$ & 11.15 & 19.41 & 21.47 & -28.39 & -18.2 & -17.04 & 22.36 & 26.29 & 30 & 13.22 & 16.01 & 12.4 \\
\hline
\end{tabular}

relate to its high content in anthocyanins, which are synthesized at later growth stages and act as antioxidant molecules against oxidative stress and salt stress in particular [34,35]. Despite minor deviations, our findings support the feasibility of conducting early selection of salt tolerant lettuce germplasm to be exploited for cultivation or integrated as germplasm material in breeding programs.

\section{References}

1. Zhao KF, Song J, Fan H, Zhou S, Zhao M. Growth response to ionic and osmotic stress of $\mathrm{NaCl}$ in salt-tolerant and salt-sensitive maize. J Integr Plant Biol. 2010; 52: 468-475.

2. Feng ZT, Sun QJ, Deng YQ, Sun SF, Zhang JG, Wang BS. Study on pathway and characteristics of ion secretion of salt glands of Limonium bicolor. Acta Physiol Plant. 2014; 36: 2729-2741.

3. Flowers TJ, Colmer TD. Salinity tolerance in halophytes. New Phytol. 2008; 179: 945-963.

4. Flowers TJ. Improving crop salt tolerance. J Exp Bot. 2004; 55: 307-319.

5. Zhou JC, Fu TT, Sui N, Guo JR, Feng G, Fan JL, et al. The role of salinity in seed maturation of the euhalophyte Suaeda salsa. Plant Biosyst. 2016 150: 83-90.

6. Bewley JD, Black M. Physiology and biochemistry of seeds in relation to germination. Hegarty TW, editor. In: Viability, Dormancy, and Environmenta Control, vol. 2. Springer, Berlin. 1982; 1399-1401.

7. Munns R, Tester M. Mechanisms of salinity tolerance. Ann Rev Plant Biol. 2008; 59: 651-681.

8. Ashraf M, Harris PJC. Potential biochemical indicators of salinity tolerance in plants. Plant Sci. 2004; 166: 3-16.

9. Zörb C, Geilfus CM, Dietz KJ. Salinity and crop yield. Plant Biol. 2019; 21: 31-38.

10. Slama I, Abdelly C, Bouchereau A, Flowers T, Savoure A. Diversity, distribution and roles of osmoprotective compounds accumulated in halophytes under abiotic stress. Ann Bot. 2015; 115: 433-447.

11. Zhu JK. Salt and drought stress signal transduction in plants. Ann Rev Plant Biol. 2002; 53: 247-273

12. Parida AK, Das AB. Salt tolerance and salinity effects on plants: A review. Ecotoxicol Environ Saf. 2005; 60: 324-349.

13. Hasegawa PM, Bressan RA, Zhu JK, Bohnert HJ. Plant cellular and molecula responses to high salinity. Ann Rev Plant Physiol Plant Mol Biol. 2000; 51 463-499.

14. Gupta S, Lakshmi AJ, Manjunath MN, Prakash J. Analysis of nutrient and antinutrient content of underutilized green leafy vegetables. LWT - Food Sci Technol. 2005; 38: 339-345.

15. Viacava GE, Gonzalez-Aguilar G, Roura SI. Determination of phytochemicals and antioxidant activity in butterhead lettuce related to leaf age and position.
J Food Biochem. 2014; 38: 352-362.

16. Shannon MC, Grieve CM. Tolerance of vegetable crops to salinity. Sci Hortic. 1999; 78: 5-38

17. Xu C, Mou B. Evaluation of lettuce genotypes for salinity tolerance. J Am Soc Hortic Sci. 2015; 50: 1441-1446.

18. Barassi CA, Ayrault G, Creus CM, Sueldo R, Sobrero MT. Seed inoculation with Azospirillum mitigates $\mathrm{NaCl}$ effects on lettuce. Sci Hortic. 2006; 109: 8-14

19. Eraslan F, Inal A, Savasturk O, Gunes A. Changes in antioxidative system and membrane damage of lettuce in response to salinity and boron toxicity. Sci Hortic. 2007; 114: 5-10

20. Mohammadi $\mathrm{P}$, Khoshgoftarmanesh $\mathrm{AH}$. The effectiveness of synthetic zinc (Zn)-amino chelates in supplying $\mathrm{Zn}$ and alleviating salt-induced damages on hydroponically grown lettuce Sci Hortic. 2014; 172: 117-123.

21. Ahmed S, Ahmed S, Roy S, Woo S, Sonawane K, Shohael A. Effect of salinity on the morphological, physiological and biochemical properties of lettuce (Lactuca sativa L.) in Bangladesh. Open Agric. 2019; 4: 361-373.

22. Ungar IA. Effects of salinity on seed germination, growth, and ion accumulation of Atriplex patula (Chenopodiaceae). Am J Bot. 1996; 83: 604-607.

23. Almansouri M, Kinet JM, Lutts S. Effect of salt osmotic stresses on germination in durum wheat (Triticum durum Desf.). Plant Soil. 2001; 231: 243-254.

24. Bojović B, Đelić G, Topuzović M, Stanković M. Effects of $\mathrm{NaCl}$ on seed germination in some species from families Brassicaceae and Solanaceae. Kragujev J Sci. 2010; 32: 83-87.

25. Foti C, Khah EM, Pavli OI. Germination profiling of lentil genotypes subjected to salinity stress. Plant Biol. 2018; 21: 480-486.

26. Al-Maskri A, Al-Kharusi L, Al-Miqbali $\mathrm{H}$, Khan MM. Effects of salinity stress on growth of lettuce (Lactuca sativa) under closed-recycle nutrient film technique. Int J Agric Biol. 2010; 12: 377-380.

27. Nasri N, Saïdi I, Kaddour R, Lachaâl M. Effect of salinity on germination, seedling growth and acid phosphatase activity in lettuce. Am J Plant Sci. 2015; 6: 57-63.

28. Ünlükara A, Cemek B, Karaman S, Erşahin S. Response of lettuce (Lactuca sativa var. crispa) to salinity of irrigation water. New Zeal J Crop Hort. 2008; 36: 265-273.

29. Garrido Y, Tudela JA, Marín A, Mestre T, Martínez V, Gil MI. Physiological, phytochemical and structural changes of multi-leaf lettuce caused by salt stress. J Sci Food Agric. 2014; 94: 1592-1599.

30. Ekinci M, Yildirim E, Dursun A, Turan M. Mitigation of salt stress in lettuce (Lactuca sativa L. var. Crispa) by seed and foliar 24-epibrassinolide treatments. Am So Hortic Sci. 2012; 47: 631-636.

31. Adhikari ND, Simko I, Mou B. Phenomic and physiological analysis of salinity effects on lettuce. Sensors. 2019; 19: 4814.

32. Kirst GO. Salinity tolerance of eukaryotic marine algae. Ann Rev Plant Physiol 
Plant Mol Biol. 1989; 41: 21-53.

33. Jamil M, Rehman S, Rha EE. Salinity effect on plant growth, PsI photochemistry and chlorophyll content in sugar beet (Beta vulgarıs L.) and cabbage (Brassiıca oleracea capitata L.). Pak J Bot. 2007; 39: 753-760.

34. Chalker-Scott L. Environmental significance of anthocyanins in plant stress responses. Photochem Photobiol. 1999; 70: 1-9.
35. Chutipaijit S, Chaum S, Sompornpailin K. High contents of proline and anthocyanin increase protective response to salinity in 'Oryza sativa' L. spp. 'indica'. Austr J Crop Sci. 2011; 5: 1191-1198. 